Article

\title{
The Fungus among Us: Cryptococcus neoformans and Cryptococcus gattii Ecological Modeling for Colombia
}

\section{Sunny Mak ${ }^{1, *}$, Nórida Vélez ${ }^{2}$, Elizabeth Castañeda ${ }^{2}$, Patricia Escandón ${ }^{2}$ and Colombian Environmental Study Group ${ }^{3,4,5,6,7}$}

1 Public Health Analytics, British Columbia Centre for Disease Control, 655 West 12th Avenue, Vancouver, BC V5Z 4R4, Canada

2 Grupo de Microbiología, Instituto Nacional de Salud, Av. Calle 26 No. 51-20, Bogotá, D.C. 111321, Colombia; E-Mails: noridavelezc@gmail.com (N.V.); ecastaneda21@gmail.com (E.C.); pescandon@ins.gov.co (P.E.)

3 Catalina de Bedout, Luz Elena Cano, Corporación para Investigaciones Biológicas, Medellín, Antioquia 055428, Colombia

4 María Clara Noguera, Universidad Metropolitana, Barranquilla, Atlántico 080001, Colombia

5 Fabiola González, Cristian Anacona, Universidad del Cauca, Popayán, Cauca 111321, Colombia

6 Jairo Lizarazo, Hospital Universitario Erasmo Meoz, Cúcuta, Norte de Santander 540004, Colombia

7 María Inés Alvárez, Universidad del Valle, Cali, Valle del Cauca 025360, Colombia

* Author to whom correspondence should be addressed; E-Mail: sunny.mak@bccdc.ca; Tel.: +1-604-707-2575; Fax: +1-604-707-2516.

Academic Editor: John R. Perfect

Received: 25 August 2015 / Accepted: 17 September 2015 / Published: 30 September 2015

\begin{abstract}
The environmental isolation of Cryptococcus spp. is typically a difficult undertaking. Collecting samples in the field is costly in terms of travel, personnel time and materials. Furthermore, the recovery rate of Cryptococcus spp. may be very low, thereby requiring a large number of samples to be taken without any guarantee of success. Ecological niche modeling is a tool that has traditionally been used to forecast the distribution of plant and animal of species for biodiversity and conservation purposes. Here, we use it in a public health application to produce risk area maps for cryptococcal disease in Colombia. The Genetic Algorithm for Ruleset Production (GARP) was used to create models for Cryptococcus neoformans (C. neoformans) and Cryptococcus gattii (C. gattii), based on environmental sampling and clinical records data recorded since 1987. These maps could be used to focus public health messaging related to cryptococcal disease, and it enables us to characterize the ecological niche for Cryptococcus in Colombia. We found that the
\end{abstract}


ecological niche for C. gattii in Colombia is quite diverse, establishing itself in sub-tropical and temperate ecoregions within the country. This suggests that $C$. gattii is highly adaptive to different ecological conditions in Colombia and different regions of the world.

Keywords: Cryptococcus; cryptococcal disease; ecological niche modeling; risk mapping

\section{Introduction}

Cryptococcus is a fungal organism (yeast cells or blastoconidia $\sim 1-2$ micrometers in size) that can cause illness in humans and animals through environmental exposure. Of particular medical interest are Cryptococcus neoformans (serotypes A, AD and D) and Cryptococcus gattii (serotypes B and C). Cryptococcus neoformans (C. neoformans) has a worldwide distribution and is typically found in bird droppings in cosmopolitan settings; those infected by $C$. neoformans are predominantly immunocompromised [1]. Conversely, the geographical distribution of Cryptococcus gattii (C. gattii) was traditionally understood to be limited to tropic and sub-tropic regions in association with Eucalyptus spp. trees [2]; however, emergence of C. gattii in the Pacific Northwest region of North America, a temperate rainforest region, has redefined the ecological niche of C. gattii $[3,4]$. The majority of $C$. gattii infections occur in immunocompetent persons.

Risk maps are useful for delineating the geographical areas where potential exposure to environmental pathogens may occur. The purpose of this study was to create ecologically-based risk maps for C. neoformans and C. gattii for Colombia to assist clinicians in the diagnosis of cryptococcal disease, and to direct public health messaging related to cryptococcal disease. This study also describes the environmental characterization of the ecological niche for C. neoformans and C. gattii for Colombia based on the environmental predictor data used in the modeling.

Previous clinical and epidemiological research performed by the Colombian Group for the Study of Cryptococcosis identified an increased incidence related to the AIDS pandemic. The mean annual incidence of cryptococcal disease in the general population between 1997-2005 and 2006-2010 remained the same at 2.4 cases per million population; whereas, in AIDS patients the incidence rate rose from 3000 cases per million population during 1997-2005 up to 3300 cases per million population during 2006-2010. The vast majority of clinical isolates recovered $(n=1074 ; 96.6 \%)$ belong to C. neoformans var. grubii (serotype A), five isolates $(0.4 \%)$ to $C$. neoformans var. neoformans (serotype D), and 33 isolates (3.0\%) to C. gattii, with Norte de Santander the department with the highest frequency of cryptococcosis cases $(77 \%)$ caused by $C$. gattii in the immunocompetent population $[5,6]$.

Several environmental approaches have been undertaken in Colombia to describe the environmental importance of the fungus and its potential association with clinical isolates. These reports have documented the isolation of $C$. neoformans var. grubii and C. gattii from diverse sources, such as Eucalyptus spp., Ficus spp. and Terminalia catappa trees, among others [7-9]. Analysis of environmental climatic factors has identified higher frequency and density of $C$. neoformans in the rainy season (particularly during the wet and humid months of April and May) than in the dry season [10], but a differential relationship between C. gattii serotypes B and C and humidity, temperature, evaporation and solar radiation in Colombia was also described [11]. 
Risk maps are typically the outcomes of models of disease transmission based on epidemiological, climatic and environmental data [12]. These models can be informed by expert opinion based on coarse scale datasets, created using statistical algorithms and geographic information systems (GIS) modeling based on spatially refined datasets, or based on observations from field sampling. The development of a cryptococcal disease risk map is challenging because the environmental isolation of Cryptococcus spp. is a difficult undertaking. Collecting samples in the field, and subsequent testing in the laboratory, is costly in terms of travel, personnel time and materials; C. neoformans and C. gattii cannot be identified with the naked eye, and these fungal organisms are not believed to adversely affect the health of its plant hosts. Furthermore, the recovery rate of Cryptococcus spp. may be very low, thereby requiring a large number of samples to be taken without any guarantee of success [13].

However, when the information is available, disease risk maps generated from ecological niche modeling can provide accurate forecasts of a pathogenic organism's ecological niche based on the environmental characteristics of its observed locations [14]. Supporting this work is the increased availability and quality of environmental data derived from remote sensing (i.e., aerial or satellite imagery) sources, and compatibility with GIS and species distribution modeling software [12]. Environmental predictor layers used in ecological niche modeling comprise of biotic (vegetation, animal, microorganism) and/or abiotic (climate, terrain, soil) data.

The concept of the ecological niche of a species is defined as the set of physical and biological conditions under which the species can maintain its population without immigration [15]. For a species to maintain its population, individuals must be able to survive and reproduce. The fundamental niche of a species consists of the total potential area that meets all the physical and biological requirements of a species (i.e., geographical space and environmental components); whereas, the realized niche of a species is comprised of the actual distribution of a species determined by a variety of factors such as dispersal, history, and physical barriers (i.e., geographical space, environmental components and species responses) [16-18]. Ecological niche modeling therefore uses observations of a species' occurrences from its realized niche, and produces a forecast of the species' fundamental niche.

The use of clinical records for disease risk mapping and assessment has proved useful in some applications $[14,19]$ but it also introduces model uncertainty because the place of environmental exposure to the infectious agent may be different than the case's location of residence (i.e., potential misclassification of the place of species occurrence). Ideally, the disease risk model would be based on environmental findings collected under a random location-sampling scheme with a high number of species presence observations from a wide geographical area. Environmental sampling results are heavily dependent on sampling effort though. Repeat sampling is often performed at historic presence locations or near the environs of reported cases. This produces reassuring results for the investigators, but from an ecological niche modeling/risk map creation perspective, it does not produce additional data points to inform the creation of the model. The likelihood of obtaining positive Cryptococcus spp. results from random sampling however are typically very low [20]. Furthermore, in the context of an emerging pathogen or geographical range expansion, the investigator must determine whether a single positive environmental observation is sufficient to determine the established presence of Cryptococcus spp. or if replicate findings after a period of time is necessary. Additionally, it is difficult to determine how many negative environmental sampling results are sufficient to classify an area as having a definitive absence of an organism. 


\section{Experimental Section}

Environmental and clinical data were managed in an Excel table (Microsoft Corp, Redmond, WA, USA) and imported into a GIS (ArcGIS 10.0, Redlands, CA, USA) for mapping and analysis. Approximate latitude and longitude coordinates from where the environmental samples were collected were derived from Google Maps (Google, Mountain View, CA, USA). Environmental sampling data were gathered from the information collected by the Colombian Microbiology Group of the National Institute of Health for the period 1987-2011; additionally, extensive environmental sampling was performed in 13 geographical departments of Colombia during the years 2012-2014 for the purpose of increasing the number of input data points to support the ecological niche modeling (Supplementary Table S1). Environmental sampling consisted of collecting plant material from different species of trees and biological samples from bird excreta. Sampling was conducted in cities where cryptococcosis cases had been reported, specifically in parks and urban areas with high density of native and introduced species of trees, as well as places where the presence of bird excreta was observed. Samples were processed using conventional techniques, inoculating the supernatant on Guizottia abyssinica agar plates supplemented with Byphenil and antibiotics. Plates were observed daily during one month, and suspected brown colonies were streaked onto Sabouraud glucose agar plates for further phenotypic characterization and species determination [21]. Additionally, one veterinary case was included, from a Canis lupus familiaris. Clinical cases recorded in the National Epidemiology Survey (a passive disease surveillance system) were geocoded to their address of residence.

Numerous ecological niche-modeling algorithms are available (envelope models, maximum entropy, rule-based, splines, classical statistics) [22]. However, fundamentally, ecological niche models are correlative models - they relate observed presences of a species to values of environmental variables at those location. We used Desktop GARP [23] because of its utility in a wide range of applications, strong user support, ability to produce reliable models with a small number of input data points and consistency with previous analyses [14,24]. Detailed description of the GARP methodology is available elsewhere [25]. In summary, GARP uses a "superset" of rules to identify the ecological niche of a species based on non-random correlations among species presence, species absence and environmental parameter values [23]. The species occurrence data are split into training and testing subsets, and the environmental data layers believed relevant to the ecology of the species in question are used to construct the model. The rules for predicting the ecological niche of a species - atomic, range, negated rate and logistic regression-are randomly developed and progressively applied on the training dataset. The rule is accepted and incorporated into the model if the change in predictive accuracy increases; otherwise, the rule is rejected and dropped [24].

Predictive accuracy of the model is calculated by dividing the number of correct predictions (i.e., predicted presence — observed presence and predicted absence-observed absence) by the total number of predictions (i.e., sum of correct and incorrect predictions). A commission error occurs when the model predicts a species to occur where it does not, and an omission error occurs when the model fails to predict a species occurrence where it does in fact occur.

We used 60 records of $C$. neoformans environmental isolations (Figure 1A) to build and test the ecological niche model for C. neoformans, and 36 records of C. gattii environmental isolations 
(11 records) and clinical cases (25 records; to increase the number of data points for the modeling; Figure 1B) to build and test the ecological niche model for C. gattii.
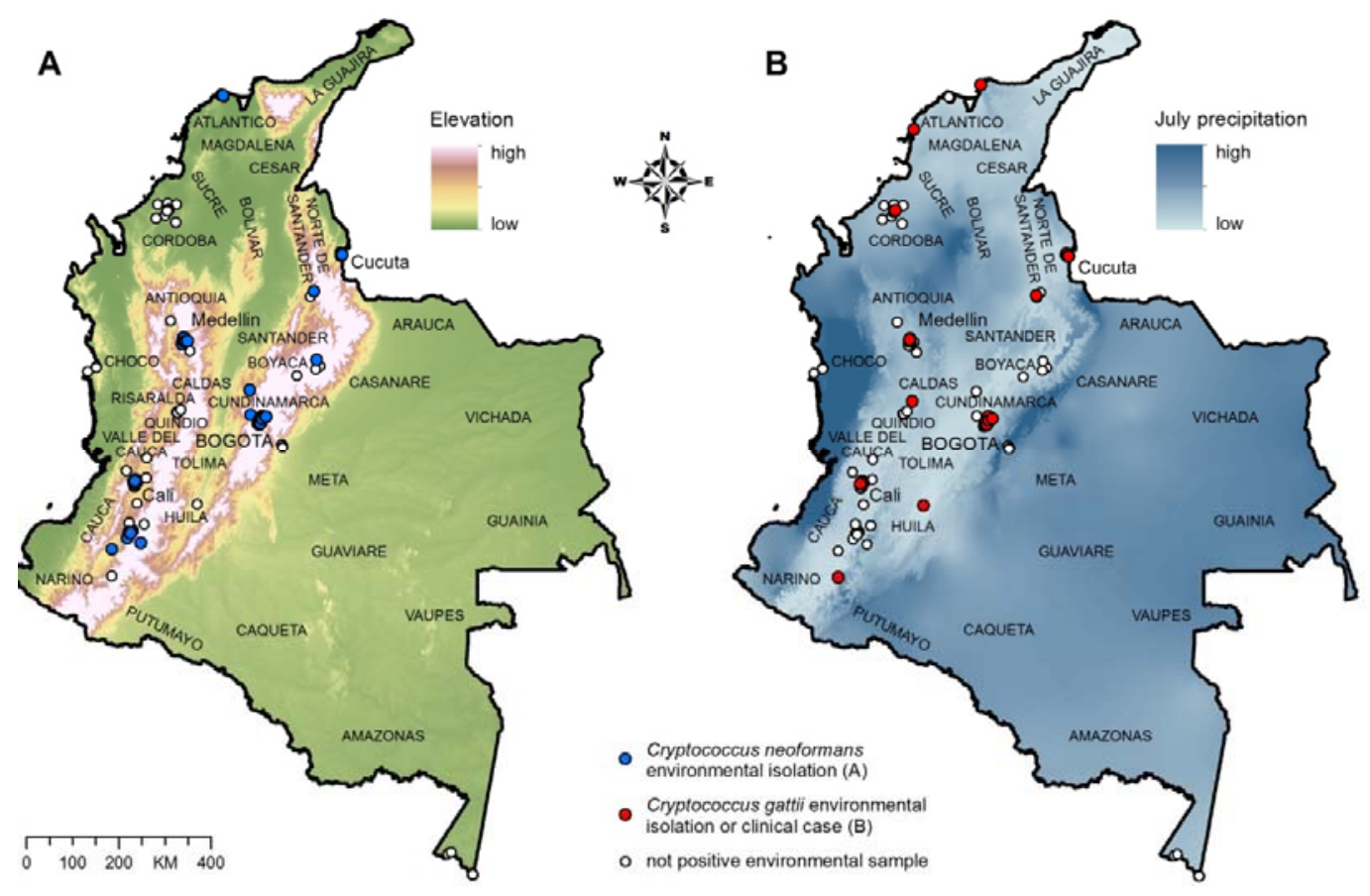

Figure 1. (A) Environmental isolation of C. neoformans; (B) Environmental isolation and clinical cases of C. gattii infection. The departments of Colombia are labeled on the map.

Further validation of the $C$. neoformans model was accomplished by overlaying the clinical reports of cryptococcal disease due to C. neoformans (51 records) to verify the predictive accuracy of the model. Details of the isolations of C. neoformans and C. gattii used to create the ecological niche models are described in Supplementary Table S2.

We used 38 environmental predictor layers (Table 1) believed to be relevant to $C$. neoformans and $C$. gattii biogeography in the ecological niche modeling: temperature, precipitation and elevation layers from WorldClim [26], land cover from the European Environment Agency [27] and the Food and Agricultural Organization of the United Nations (FAO) [28], soil type from the FAO [29] and maximum green vegetation fraction (2001-2012 average) from the United States Geological Survey [30]. The spatial resolution of these datasets is $1 \mathrm{~km}$ with geographical coverage over the entire extent of Colombia. Slope and aspect direction were calculated from the elevation data layer using the Spatial Analyst extension of ArcGIS. A jack-knifing procedure was performed to identify environmental layers that are good predictors for Cryptococcus spp. using Desktop GARP. The C. neoformans and C. gattii input datasets were split into $50 \%$ training and 50\% testing subsets to build and test the models. The environmental data layers were jack-knifed individually through 30 model runs for C. neoformans and C. gattii. Each model run comprised of up to 1000 iterations or until convergence was reached. 
Table 1. List of environmental data layers used in the ecological niche models. Data layers with $\geq 80 \%$ training and testing accuracy for $C$. neoformans and $C$. gattii from the jack-knifing procedure are indicated ("yes").

\begin{tabular}{|c|c|c|c|}
\hline Layer & Source & C. neoformans Model & C. gattii Model \\
\hline Annual mean temperature & \multirow{32}{*}{ WorldClim } & - & - \\
\hline Mean diurnal range & & - & - \\
\hline Isothermality & & - & - \\
\hline Temperature seasonality & & - & - \\
\hline Maximum temperature of warmest month & & - & - \\
\hline Minimum temperature of coldest month & & - & - \\
\hline Temperature annual range & & - & - \\
\hline Mean temperature of wettest quarter & & - & - \\
\hline Mean temperature of driest quarter & & - & - \\
\hline Mean temperature of warmest quarter & & - & - \\
\hline Mean temperature of coldest quarter & & - & - \\
\hline Annual precipitation & & - & yes \\
\hline Precipitation of wettest month & & - & yes \\
\hline Precipitation of driest month & & - & - \\
\hline Precipitation seasonality & & - & - \\
\hline Precipitation of wettest quarter & & - & yes \\
\hline Precipitation of driest quarter & & - & - \\
\hline Precipitation of warmest quarter & & - & - \\
\hline Precipitation of coldest quarter & & - & yes \\
\hline January precipitation & & - & - \\
\hline April precipitation & & yes & yes \\
\hline July precipitation & & yes & yes \\
\hline October precipitation & & - & - \\
\hline Mean January maximum temperature & & - & - \\
\hline Mean April maximum temperature & & - & - \\
\hline Mean July maximum temperature & & - & - \\
\hline Mean October maximum temperature & & - & - \\
\hline Mean January minimum temperature & & - & - \\
\hline Mean April minimum temperature & & - & - \\
\hline Mean July minimum temperature & & yes & - \\
\hline Mean October minimum temperature & & yes & - \\
\hline Elevation & & yes & - \\
\hline Aspect & \multirow{2}{*}{ derived from WorldClim } & - & - \\
\hline Slope & & - & - \\
\hline Global land cover-2000 & Europa & - & - \\
\hline Global land cover-SHARE 2014 & \multirow{2}{*}{ FAO } & - & yes \\
\hline Dominant soil type & & - & - \\
\hline Maximum green vegetation fraction & USGS & - & yes \\
\hline
\end{tabular}

Environmental data layers with training and testing accuracies $\geq 80 \%$ were used to create the final ecological niche models for C. neoformans and C. gattii. For these final model runs, the input 
C. neoformans and C. gattii data were again divided into training (50\%) and testing (50\%) subsets, and 50 model runs were performed. Each model run produced a binary value output data layer with 1 indicating areas with suitable ecological conditions to support C. neoformans and C. gattii, respectively, and 0 indicating unsuitable areas. The 50 output data layers where overlaid and summed to produce a final, composite ecological niche map for C. neoformans and C. gattii.

Lastly, we used our expert opinion to critically assess the predicted ecological niche model output for C. neoformans and C. gattii. We reclassified geographical areas above $3000 \mathrm{~m}$ elevation as "not suitable" for C. neoformans and C. gattii because the Páramo climate altitudinal zone (3000-4000 m above sea level) is characterized by temperature below $10^{\circ} \mathrm{C}$ with icy winds and frequent snowfall, and the glacial climate altitudinal zone $(>4000 \mathrm{~m})$ is characterized by glaciers [31]. These conditions are not believed to be conducive for $C$. neoformans and C. gattii based on previous environmental sampling findings in Colombia, and observations from Vancouver Island, Canada [11,14,32].

\section{Results and Discussion}

April and July precipitation, mean July and October minimum temperature, and elevation had training and testing accuracy $\geq 80 \%$ based on the jack-knifing procedure of environmental data layers against the distribution of C. neoformans environmental isolations (Table 1; Figure 1A). Annual, April and July precipitation, precipitation of the wettest month, wettest quarter and coldest quarter, land cover, and maximum green vegetation fraction had training and testing accuracy $\geq 80 \%$ based on the jack-knifing procedure of environmental data layers against the distribution of C. gattii environmental isolations and clinical cases (Table 1; Figure 1B). These environmental data layers were used to produce the final ecological niche models for C. neoformans (Figure 2A) and C. gattii (Figure 2B).
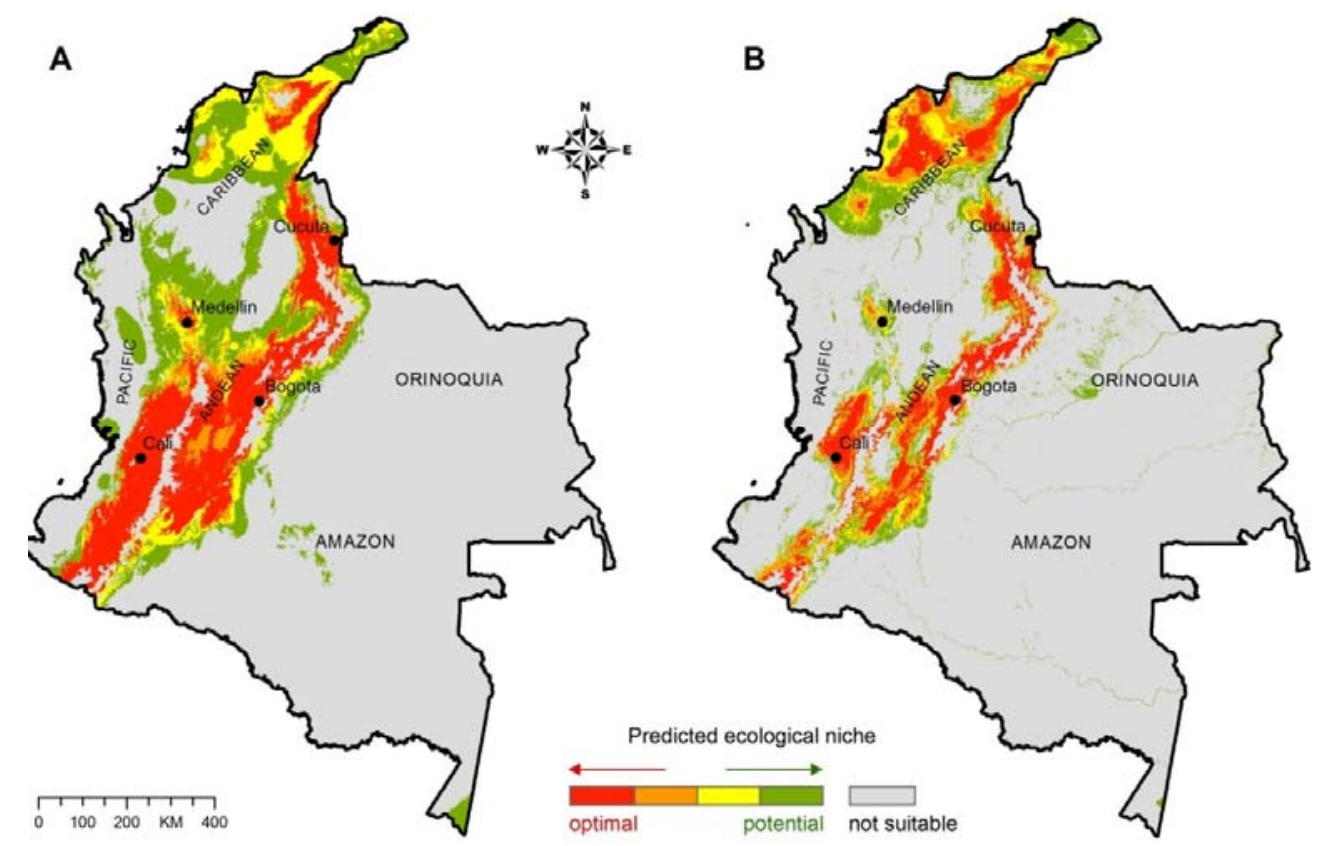

Figure 2. (A) Ecological niche model for C. neoformans; (B) Ecological niche model for $C$. gattii. The major ecoregions of Colombia are labeled on the map. 
The prediction model for C. neoformans in Colombia revealed the presence of optimal ecological niche areas along the mountainous Andean natural region, extending from the department of Cauca in western Colombia through to the department of Magdalena in northwestern Colombia (Figure 2A). This mountain range is comprised of several heavily populated departments such as Cundinamarca (Bogotá, capital city), Boyacá and Santander, and an important number of cryptococcosis cases have been reported from this region [6]. Furthermore, numerous environmental isolations of C. neoformans have been detected in this region (Figure 1A). Potentially, the ecological niche model suggests that the fungus may be present in very low, not yet detected concentration, or may disperse in the future to the Caribbean region along the northern coast of the country. The prediction model for $C$. neoformans in Colombia had a final training accuracy of $91.6 \%$ and testing accuracy of $86.4 \%$.

The predicted ecological niche areas for C. gattii follow a similar, but less extensive, geographical distribution (Figure 2B). These regions are generally characterized as the warm climate altitudinal zone positioned between sea level and $1000 \mathrm{~m}$ elevation, having temperatures above $24{ }^{\circ} \mathrm{C}$ and heavy rains (the cities of Cali and Cúcuta for example), the temperate climate altitudinal zone positioned between 1000 and $2000 \mathrm{~m}$ above sea level, having temperatures between 17 and $22{ }^{\circ} \mathrm{C}$, and annual precipitation between 2000 and $2500 \mathrm{~mm}$ (the city of Medellin for example), and the cold climate altitudinal zone positioned between 2000 and $3000 \mathrm{~m}$ above sea level, having temperatures between 10 and $17{ }^{\circ} \mathrm{C}$, and annual precipitation above $2000 \mathrm{~mm}$ (the city of Bogotá for example) [33]. The prediction model for $C$. gattii in Colombia had a final training accuracy of $92.9 \%$ and testing accuracy of $89.1 \%$.

Not suitable ecological niche areas for C. gattii and C. neoformans include the tropical rainforest regions (hot and high humidity climate with heavy rainfall) along the Pacific coast and Amazon River basin, and the Orinoquia region in western Colombia (Figure 2A,B).

Overall, the environmental characterization of $C$. neoformans and C. gattii based on empirical data correlated with the environmental characterization of $C$. neoformans and C. gattii based on prediction modeling (Table 2). The minor to moderate variations between empirical data and prediction modeling reflect the iterative, evolving nature of the decision rule based GARP algorithm. Precipitation (April, July, annual, wettest month, wettest quarter, coldest quarter) appears to have a major role in determining the ecological niche for C. gattii.

The environmental data layers used for the creation of the model show that Colombia has a group of macro-ecologic variables where the presence of the fungi is suitable. The country of Colombia is strategically positioned in the South American continent, crossed by the Equatorial zone, which determines the existence of a wide variety of climates and ecosystems; therefore, the country does not have traditional seasons, but instead only a rainy winter and a dry summer. 
Table 2. Environmental characterization of $C$. neoformans based on field observations and C. gattii based on field observations and clinical reports, and environmental characterization of C. neoformans and C. gattii based on ecological niche modeling (top quartile of models).

\begin{tabular}{|c|c|c|c|c|c|c|}
\hline C. neoformans & \multicolumn{3}{|c|}{ Based on Field Observations } & \multicolumn{3}{|c|}{ Based on Ecological Niche Modeling } \\
\hline Layer & Minimum & Mean & Maximum & Minimum & Mean & Maximum \\
\hline Elevation (m) & 9 & 1425 & 2618 & 291 & 1673 & 3542 \\
\hline April precipitation (mm) & 68 & 141 & 360 & 25 & 156 & 455 \\
\hline July precipitation (mm) & 24 & 75 & 471 & 4 & 64 & 151 \\
\hline $\begin{array}{l}\text { Mean July minimum } \\
\text { temperature }\left({ }^{\circ} \mathrm{C}\right)\end{array}$ & 8.0 & 15.4 & 22.9 & 3.3 & 13.6 & 22.9 \\
\hline $\begin{array}{l}\text { Mean October minimum } \\
\text { temperature }\left({ }^{\circ} \mathrm{C}\right)\end{array}$ & 8.3 & 15.3 & 22.8 & 3.5 & 13.9 & 22.5 \\
\hline C. gattii & \multicolumn{3}{|c|}{$\begin{array}{c}\text { Based on Field Observations } \\
\text { and Clinical Reports }\end{array}$} & \multicolumn{3}{|c|}{ Based on Ecological Niche Modeling } \\
\hline Layer & Minimum & Mean & Maximum & Minimum & Mean & Maximum \\
\hline April precipitation (mm) & 17 & 117 & 224 & 4 & 117 & 338 \\
\hline July precipitation (mm) & 24 & 57 & 154 & 1 & 75 & 223 \\
\hline Annual precipitation (mm) & 529 & 1016 & 1951 & 437 & 1095 & 1868 \\
\hline $\begin{array}{c}\text { Precipitation of } \\
\text { wettest month }(\mathrm{mm})\end{array}$ & 101 & 147 & 267 & 59 & 159 & 357 \\
\hline $\begin{array}{c}\text { Precipitation of } \\
\text { wettest quarter (mm) }\end{array}$ & 246 & 365 & 706 & 166 & 411 & 813 \\
\hline $\begin{array}{c}\text { Precipitation of } \\
\text { coldest quarter }(\mathrm{mm})\end{array}$ & 31 & 234 & 634 & 1 & 226 & 702 \\
\hline $\begin{array}{c}\text { Maximum green } \\
\text { vegetation fraction }(\%)\end{array}$ & 23 & 58 & 99 & 1 & 90 & 100 \\
\hline Land cover & \multicolumn{3}{|c|}{$\begin{array}{l}82 \% \text { grassland, } 12 \% \text { tree cover, } \\
3 \% \text { cropland, } 3 \% \text { sparse vegetation }\end{array}$} & \multicolumn{3}{|c|}{$\begin{array}{c}48 \% \text { tree cover, } 34 \% \text { grassland, } 14 \% \\
\text { cropland, } 2 \% \text { shrubs, } 1 \% \text { waterbodies, } \\
1 \% \text { other }\end{array}$} \\
\hline
\end{tabular}

A limitation of this study is the paucity of environmental sampling data from much of the rural and remote areas of Colombia such as the vast Amazonas and Orinoquia regions. Extensive sampling ( $>18000$ environmental samples) was performed in 13 departments where cases of cryptococcal disease have been reported, where C. neoformans and C. gattii have been previously isolated in the environment, and in areas of particular epidemiological and ecological interest (Figure 1; Supplementary Table S1). Environmental sampling was performed in a small area of the Amazonas, which yielded no positive findings; unfortunately, it was not feasible to conduct more extensive environmental sampling in the other regions of the Amazonas or in the Orinoquia region for this study. We acknowledge that absence of data from these regions have the potential to negatively affect the prediction model because data in the pluvial forest regions excludes these environmental parameters from the final model; however, the predictions presented in this study are the best available based on the empirical data collected over the past 10 years.

Another limitation of this study is the use of C. gattii clinical case data to augment the environmental observations for the predictive modeling. This introduces uncertainty as to whether the case's place of 
residence was in fact the place of exposure to C. gattii in the environment, and it has the potential to result in modeling error. However, Mak et al. [14] have demonstrated the successful use of ecological niche modeling based on human and animal C. gattii disease surveillance data. Furthermore, validation of the $C$. neoformans model based on field observations was accomplished by overlaying the clinical reports of cryptococcal disease due to $C$. neoformans (The $C$. neoformans clinical dataset was not used to train or test the $C$. neoformans prediction model based on field observations). Of the 51 clinical records, 50 were located within the forecasted ecological niche of $C$. neoformans, thereby further validating the predictive accuracy of the model.

Further refinement of the prediction models may include dividing $C$. neoformans into C. neoformans var. grubii and C. neoformans var. neoformans as separate species, and the five species within C. gattii-in recognition of the new taxonomy of the C. neoformans/C. gattii species complex recently proposed by Hagen and colleagues [34]. However, this may only be possible if sufficient data are available to train and test the new models. Additional sampling, especially from geographically diverse locations throughout Colombia, would be required.

Lastly, it is important to note that the prediction models for C. neoformans and C. gattii describe the ecological niche areas for these fungal species at the regional scale. The actual habitat suitability and ultimate presence of $C$. neoformans and C. gattii at a specific location at the site level is highly variable because there will most likely be considerable ecological heterogeneity within each $1 \mathrm{~km}$ by $1 \mathrm{~km}$ spatial unit in the ecological niche model. Instead, the maps can be used by clinicians to consider the diagnosis of cryptococcal disease for patients residing in or having recent travel to these geographical areas.

\section{Conclusions}

In this study we describe the utility of ecological niche modeling to produce risk maps for C. neoformans and C. gattii for Colombia. We found that the ecological niche for C. gattii in Colombia is quite diverse, establishing itself in sub-tropical and temperate ecoregions within the country. This suggests that $C$. gattii is highly adaptive to different ecological conditions in Colombia and different regions of the world. Furthermore, the modeling software (Desktop GARP) and environmental predictor layers used in this study are available at no cost, and the methodology is applicable to other jurisdictions and fungal organisms.

\section{Acknowledgments}

We thank Departamento Administrativo de Ciencia, Tecnologia e Innovacion, Colciencias for financial support of this work (grant number: 2011-3600115683).

\section{Author Contributions}

Sunny Mak and Patricia Escandón conceived and designed the models; Sunny Mak, Nórida Vélez and Patricia Escandón performed the modeling and analyzed the data; Sunny Mak, Nórida Vélez, Patricia Escandón and Elizabeth Castañeda contributed reference data; Sunny Mak, Nórida Vélez, Patricia Escandón and Elizabeth Castañeda wrote the paper. 


\section{Conflicts of Interest}

The authors declare no conflict of interest.

\section{References}

1. Mitchell, T.G.; Castañeda, E.; Nielsen, K.; Wanke, B.; Lazera, M.S. Environmental niches for Cryptococcus neoformans and Cryptococcus gattii. In Cryptococcus: From human pathogen to model yeast; Heitman, J., Kozel, T.R., Kwon-Chung, K.J., Perfect, J.R., Casadevall, A., Eds; ASM Press: Washington, WA, USA, 2011; pp. 237-259.

2. Ellis, D.H.; Pfeiffer, T.J. Natural habitat of Cryptococcus neoformans var. gattii. J. Clin. Microbiol. 1990, 28, 1642-1644.

3. Kidd, S.E.; Hagen, F.; Tscharke, R.L.; Huynh, M.; Bartlett, K.H.; Fyfe, M.; MacDougall, L.; Boekhout, T.; Kwon-Chung, K.J.; Meyer, W. A rare genotype of Cryptococcus gattii caused the cryptococcosis outbreak on Vancouver Island (British Columbia, Canada). Proc. Natl. Acad. Sci. USA. 2004, 101, 17258-17263.

4. Datta, K.; Bartlett, K.H.; Baer, R.; Byrnes, E.; Galanis, E.; Heitman, J.; Hoang, L.; Leslie, M.J.; MacDougall, L.; Magill, S.S.; et al. Cryptococcus gattii Working Group of the Pacific Northwest. Spread of Cryptococcus gattii into Pacific Northwest region of the United States. Emerg. Infect. Dis. 2009, 15, 1185-1191.

5. Lizarazo, J.; Linares, M.; de Bedout, C.; Restrepo, A.; Agudelo, C.I.; Castañeda, E.; Grupo Colombiano para el Estudio de la Criptococosis. [Results of nine years of the clinical and epidemiological survey on cryptococcosis in Colombia, 1997-2005]. Biomédica 2007, 27, 94-109. (In Spanish)

6. Escandón, P.; de Bedout, C.; Lizarazo, J.; Agudelo, C.I.; Tobón, A.; Bello, S.; Restrepo, A.; Castañeda, E.; Grupo Colombiano para el Estudio de la Criptococosis. Cryptococcosis in Colombia: Results of the national surveillance program for the years 2006-2010. Biomédica 2012, 32, 386398. (In Spanish)

7. Callejas, A.; Ordoñez, N.; Rodriguez, M.C.; Castañeda, E. First isolation of Cryptococcus neoformans var. gattii, serotype C, from the environment in Colombia. Med. Mycol. 1998, 36, 341-344.

8. Escandón, P.; Quintero, E.; Granados, D.; Huérfano, S.; Ruiz, A.; Castañeda, E. [Isolation of Cryptococcus gattii serotype B from detritus of Eucalyptus trees in Colombia]. Biomédica 2005, 25, 390-397. (In Spanish)

9. Firacative, C.; Torres. G.; Rodríguez, M.C.; Escandón, P. First environmental isolation of Cryptococcus gattii serotype B, from Cúcuta, Colombia. Biomédica 2011, 31, 118-123.

10. Granados, D.P.; Castañeda, E. Isolation and characterization of Cryptococcus neoformans varieties recovered from natural sources in Bogotá, Colombia, and study of ecological conditions in the area. Microb. Ecol. 2005, 49, 282-290.

11. Granados, D.P.; Castañeda, E. Influence of climatic conditions on the isolation of members of the Cryptococcus neoformans species complex from trees in Colombia from 1992-2004. FEMS Yeast Res. 2006, 6, 636-644. 
12. Kitron, U. Risk maps: Transmission and burden of vector-borne diseases. Parasitol. Today 2000, $16,324-325$.

13. Fraser, J.A.; Lim, S.M.; Diezmann, S.; Wenink, E.C.; Arndt, C.G.; Cox, G.M.; Dietrich, F.S.; Heitman, J. Yeast diversity sampling on the San Juan Islands reveals no evidence for the spread of the Vancouver Island Cryptococcus gattii outbreak to this locale. FEMS Yeast Res. 2006, 6, 620-624.

14. Mak, S.; Klinkenberg, B.; Bartlett, K.; Fyfe, M. Ecological niche modeling of Cryptococcus gattii in British Columbia, Canada. Environ. Health Perspect. 2010, 118, 653-658.

15. Grinnell, J. Field tests of theories concerning distributional control. Am. Nat. 1917, 51, 115-128.

16. Hutchinson, G.E. Homage to Santa Rosalia, or why are there so many kinds of animals? Am. Nat. 1959, 93, 145-159.

17. Morrison, M.L.; Marcot, B.G.; Mannan, R.W. Wildlife-Habitat Relationships: Concepts and Applications; University of Wisconsin Press: Madison, WI, USA, 1992.

18. Nielsen. K.; de Obaldia, A.L.; Heitman, J. Cryptococcus neoformans mates on pigeon guano: Implications for the realized ecological niche and globalization. Eukaryot. Cell. 2007, 6, 949-959.

19. Glass, G.E.; Schwartz, B.S.; Morgan, J.M.; Johnson, D.T.; Noy, P.M.; Israel, E. Environmental risk factors for Lyme disease identified with geographic information systems. Am. J. Public Health 1995, 85, 944-948.

20. Chowdhary, A.; Rhandhawa, H.S.; Prakash, A.; Meis, J.F. Environmental prevalence of Cryptococcus neoformans and Cryptococcus gattii in India: An update. Crit. Rev. Microbiol. 2012, 38, 1-16.

21. Escandón, P.; Sánchez, A.; Firacative, C.; Castañeda E. Isolation of Cryptococcus gattii molecular type VGIII, from Corymbia ficifolia detritus in Colombia. Med. Mycol. 2010, 48, 675-678.

22. Guisan, A.; Thuiller, W. Predicting species distributions: Offering more than simple habitat models. Ecol Lett. 2005, 8, 993-1009.

23. University of Kansas Center for Research. Desktop GARP. Available online: http://www.nhm.ku.edu/desktopgarp (accessed on 31 July 2015).

24. Peterson, A.T. Predicting species' geographic distributions based on ecological niche modeling. Condor 2001, 103, 599-605.

25. Stockwell, D.; Peters, D. The GARP modelling system: Problems and solutions to automated spatial prediction. Int. J. Geogr. Inform. Sci. 1999, 13, 143-158.

26. WorldClim - Global climate data. Available online: http://www.worldclim.org (accessed on 31 July 2015).

27. European Environment Agency (EEA). Global land cover 2000. Available online: http://www.eea.europa.eu/data-and-maps/data/global-land-cover-2000-europe (accessed on 31 July 2015).

28. Food and Agricultural Organization of the United Nations (FAO). Global land cover: SHARE of year 2014. Available online: http://www.glcn.org/databases/lc_glcshare_en.jsp (accessed on 31 July 2015).

29. Food and Agricultural Organization of the United Nations (FAO). Digital soil map of the world. Available online: http://www.fao.org/geonetwork/srv/en/metadata.show?id=14116 (accessed on 31 July 2015). 
30. United States Geological Survey (USGS). $1 \mathrm{~km}$ MODIS-based maximum green vegetation fraction. Available online: http://landcover.usgs.gov/green_veg.php (accessed on 31 July 2015).

31. Instituto Geográfico Agustín Codazzi. (Climatic zones of Colombia). Available online: http://geoportal.igac.gov.co/mapas_de_colombia/IGAC/Tematicos2012/ZonificacionClimatica.pdf (accessed on 13 August 2015).

32. Quintero, E.; Castañeda, E.; Ruiz, A. [Environmental distribution of Cryptococcus neoformans in the department of Cundinamarca-Colombia]. Rev. Iberoam Micol. 2005, 22, 93-98. (In Spanish)

33. Instituto Geográfico Agustín Codazzi. [Geographic regions of Colombia]. Available online: http://geoportal.igac.gov.co/mapas_de_colombia/IGAC/Tematicos2012/RegionesGeograficas.pdf (accessed on 7 August 2015). (In Spanish)

34. Hagen, F.; Khayhan, K.; Theelen, B.; Kolecka, A.; Polacheck, I.; Sionov, E.; Falk, R.; Parnmen, S.; Lumbsch, H.T.; Boekhout, T. Recognition of seven species in the Cryptococcus gattii/ Cryptococcus neoformans species complex. Fungal Genet. Biol. 2015, 78, 16-48.

(C) 2015 by the authors; licensee MDPI, Basel, Switzerland. This article is an open access article distributed under the terms and conditions of the Creative Commons Attribution license (http://creativecommons.org/licenses/by/4.0/). 